\title{
Separation and Recovery of Antimony from High Arsenic-bearing Flue Dusts through Selective Oxidation Using $\mathrm{MnO}_{2}$
}

\author{
Lei LI, ${ }^{*}$ Fuyou WANG, Dapeng ZHONG, Cheng TAN and Yong YU \\ State Key Laboratory of Complex Non-ferrous Metal Resources Clean Utilization, Engineering Research Center of Metallurgical \\ Energy Conservation and Emission Reduction of Ministry of Education, Faculty of Metallurgical and Energy Engineering, \\ Kunming University of Science and Technology, Kunming, 650093 China.
}

(Received on January 12, 2016; accepted on November 10, 2016; J-STAGE Advance published date: February 3, 2017)

\begin{abstract}
The recovery of antimony from high arsenic-bearing flue dusts was carried out by a selective oxidation roasting process using $\mathrm{MnO}_{2}$, in which the arsenic was removed through a volatilization and antimony was oxidized to $\mathrm{Sb}_{2} \mathrm{O}_{4}$ staying in the roasted products. In a certain range, the $\mathrm{MnO}_{2}$ additive has an active effective on the arsenic volatilization for the reason that structures of some complicated As-Sb phases were destroyed after the $\mathrm{Sb}_{2} \mathrm{O}_{3}$ being oxidized to $\mathrm{Sb}_{2} \mathrm{O}_{4}$ and this part of arsenic continued to volatile. About $90.06 \%$ arsenic and only about $6.89 \%$ antimony went into smoke under the condition of roasting temperature of $723.0 \mathrm{~K}, \mathrm{MnO}_{2}$ amount of $20.5 \%$, and roasting time of $90 \mathrm{~min}$. The $\mathrm{MnO}_{2}$ selective oxidation provided a good separation of arsenic from high arsenic-bearing flue dusts. The left antimony existing in the roasted products can be reclaimed through a process of reduction roasting and dust collection.
\end{abstract}

KEY WORDS: high arsenic-bearing flue dusts; separation of arsenic and antimony; selective oxidation; $\mathrm{MnO}_{2}$; waste utilization.

\section{Introduction}

Flue dusts are generated in many pyrometallurgical processes of metal extraction, which represent not only secondary resources of many valuable metals but also potential risks of environmental contamination. ${ }^{1-3)}$ Among them, an arsenic-bearing flue dust is one of the most important secondary resources, which contains a large amount of valuable metals, such as lead, antimony and indium. ${ }^{4-7)}$ Composition of arsenic-bearing dusts varies mainly according to the type of reactor and the raw material used. During the smelting and converting process, around $60 \%$ of As and $30-40 \%$ of $\mathrm{Sb}$ from the raw material are transferred into the flue dust. ${ }^{8)}$ These dusts can not be directly recycled to the smelters or converters, because of the increase of required energy for smelting or converting process. ${ }^{9,10)}$ It is necessary to treat the flue dust separately to recover valuable metals.

Based on distinctions of volatility and water-solubility of arsenic and antimony compounds, there are many studies on treating arsenic-bearing materials by pyrometallurgy or hydrometallurgy process. ${ }^{4-7,11-14)}$ Pyrometallurgy processes containing methods of oxidation roasting, reduction roasting and chlorination roasting, usually lead to secondary arsenic pollution and high energy consumption. ${ }^{15,16)}$ Most research focused on treatment of arsenic-bearing materials by hydrometallurgical methods. The dusts were firstly leached with water, different acid solutions, ${ }^{17)} \mathrm{NaOH}$ solution, mixed

* Corresponding author: E-mail: tianxiametal1008@163.com DOI: http://dx.doi.org/10.2355/isijinternational.ISIJINT-2016-362 solution of $\mathrm{NaHS} / \mathrm{NaOH}^{18,19)}$ or sodium-sulfide solution, ${ }^{20)}$ and then hydrocyclone classification was executed on the obtained residues. Generally, the solidification process of arsenic through the formation of a stable and insoluble ferric arsenate compound in the leaching is the conventional thought for the separation of As from other elements, and it is more economical. ${ }^{15)}$ Obviously, the hydrometallurgy processes have drawbacks such as complex process flows, high consumption of chemical reagents and high cost in operation.

In this paper, an effective and environmental friendly method separating arsenic through a method of selective oxidation using $\mathrm{MnO}_{2}$ is proposed. Further, the effects of different process parameters on the separation of arsenic were initially investigated in order to determinate the optimal conditions for increasing separation rate.

\section{Experimental}

\subsection{Materials and Methods}

The high arsenic-bearing flue dust used in this study was provided by a plant for treating tin anode slime using a pyrometallurgy process locating in Yunnan province, China. The dust was crushed, ground, and screened using a 200 mesh sieve. The chemical composition (mass\%) of it is depicted in Table 1. Table 1 shows that the major elements are arsenic and antimony, and the antimony content is of $28.72 \%$, being well worth to be reclaimed. "Others" in Table 1 is mainly composed of "O" (existing as $\mathrm{As}_{2} \mathrm{O}_{3}$ and $\mathrm{Sb}_{2} \mathrm{O}_{3}$ etc.). Figure 1 shows that the main phases 
are $\mathrm{As}_{2} \mathrm{O}_{3}, \mathrm{Sb}_{2} \mathrm{O}_{3}, \mathrm{As}_{4} \mathrm{O}_{6}$ and (Sb,As) $)_{2} \mathrm{O}_{3}$, and Fig. 2 and Table 2 also show that the dust mainly contains phases of arsenic and antimony. Specifically, most arsenic-containing phases occur independently in the form of $\mathrm{As}_{2} \mathrm{O}_{3}$, and most antimony is embedded in arsenic-containing complicated phases. Deduced from Table 2, the main compositions of altered red sulfur arsenic antimony sodium ore, altered allemontite and varieties white arsenic in Fig. 2 are $\mathrm{As}_{2} \mathrm{O}_{3}$ and $\mathrm{Sb}_{2} \mathrm{O}_{3}$, and they mainly exist in the phase of ( $\left.\mathrm{Sb}, \mathrm{As}\right)_{2} \mathrm{O}_{3}$ as shown in Fig. 1. The chemicals used in all experiments were analytical reagent grade, manufactured by Tianjin Fengchun Chemical Reagent Co., Ltd.

Table 1. Chemical composition of the high arsenic-bearing flue dust $(\%$, mass $)$.

\begin{tabular}{cccccccc}
\hline Elements & $\mathrm{As}$ & $\mathrm{Bi}$ & $\mathrm{Cu}$ & $\mathrm{Fe}$ & $\mathrm{Pb}$ & $\mathrm{Sb}$ & Others \\
\hline Contents & 36.28 & 0.68 & 0.24 & 1.13 & 2.06 & 28.72 & 30.89 \\
\hline
\end{tabular}

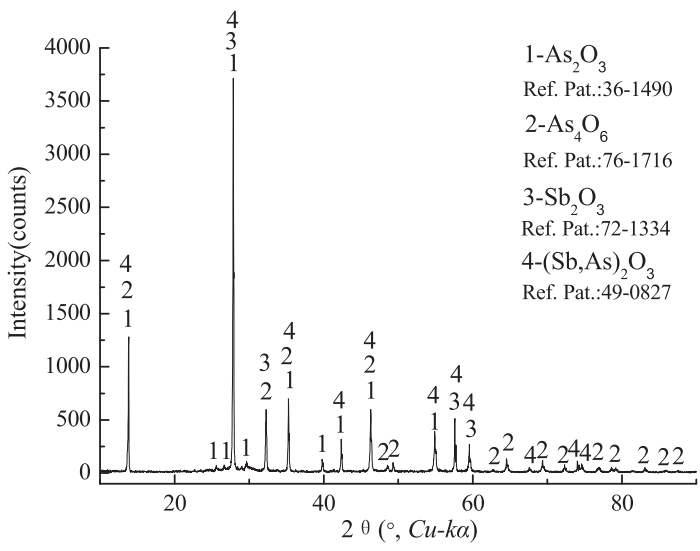

Fig. 1. XRD pattern of the high arsenic-bearing flue dust.
The roasting experiments were conducted in an electric furnace, as shown in Fig. 3. Where, the furnace plug made of ceramics was used to make the temperature in constant temperature area relatively stable, and the furnace cover fixed with a flange was used to sealing up the furnace. A $\mathrm{Pt} / \mathrm{Pt}-\mathrm{Rh}$ thermocouple in an alumina sheath was introduced into the furnace to monitor the temperature. The furnace was heated to a fixed temperature under a continuous flow of nitrogen $5.00^{*} 10^{-6} \mathrm{~m}^{3} / \mathrm{s} .5 \mathrm{~g}$ of high arsenic-bearing flue dust samples were used in every experiment, and addition amount of $\mathrm{MnO}_{2}$ reagent was calculated based on the quality ratio of it to the high arsenic-bearing flue dust used. After mixed carefully, mixtures of high arsenic-bearing flue dusts and $\mathrm{MnO}_{2}$ were roasted in a tube furnace in the range of 573-823.0 K under $\mathrm{N}_{2}$ atmosphere. The off-gas from the reaction tube was continuously passed through a water-cooled condenser, which collected the volatile matter, and then was directed to solutions of $1 \mathrm{M} \mathrm{NaOH}$ to remove harmful components (Fig. 3). After a proper time held, the reactor was cooling down in the furnace tube under $\mathrm{N}_{2}$ atmosphere to room temperature, and then pulled out for analysis.

\subsection{Instrumentation}

The thermo gravimetric analysis (TG) and differential scanning calorimetry (DSC) of the samples were performed on a thermal analyzer (NETZSCH, STA 449 F3). The typical measurements were performed at a heating rate of 0.083 $\mathrm{K} / \mathrm{s}$ under $\mathrm{N}_{2}$ atmosphere. The chemical composition and mineralogy of the samples were characterized by chemical analysis, scanning electron microscope (SEM), and electron probe microanalysis (EPMA). Phase compositions of all samples were detected by X-ray diffraction (The emission target of XRD was $\mathrm{Cu}-\mathrm{K} \alpha$, the step width was $0.01^{\circ}$, the
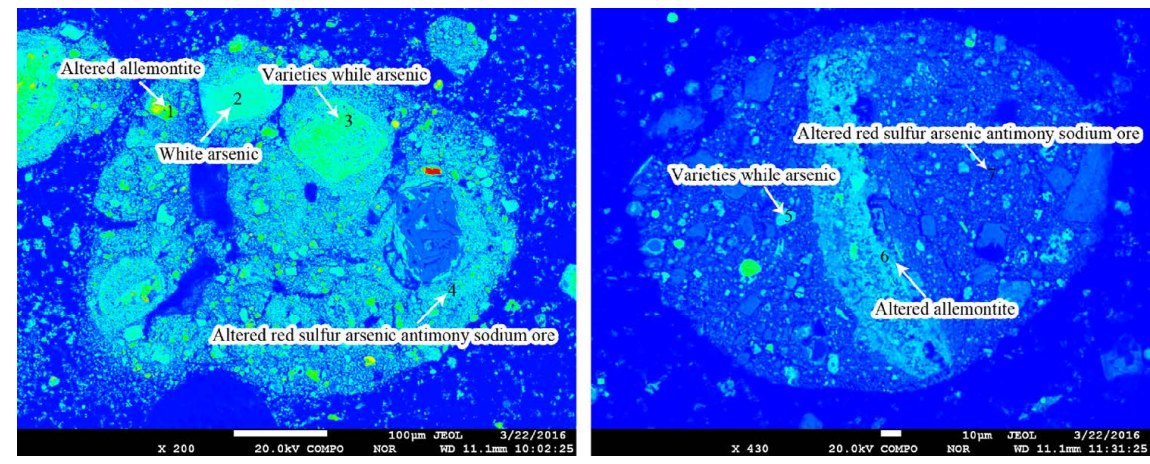

Fig. 2. Mineral phase's distribution obtained by EPMA. (Online version in color.)

Table 2. EPMA point analysis of samples shown in Fig. 2 (\%, mass).

\begin{tabular}{cccccccccc}
\hline Point & $\mathrm{Na}_{2} \mathrm{O}$ & $\mathrm{As}_{2} \mathrm{O}_{3}$ & $\mathrm{SiO}_{2}$ & $\mathrm{SO}_{3}$ & $\mathrm{FeO}$ & $\mathrm{CuO}$ & $\mathrm{Sb}_{2} \mathrm{O}_{3}$ & $\mathrm{Cr}_{2} \mathrm{O}_{3}$ & $\mathrm{PbO}$ \\
\hline 1 & 0.038 & 34.883 & 0.290 & 0.000 & 0.000 & 0.838 & 34.802 & 0.070 & 29.079 \\
2 & 0.000 & 99.073 & 0.249 & 0.130 & 0.004 & 0.077 & 0.311 & 0.149 & 0.006 \\
3 & 0.060 & 56.766 & 0.104 & 0.176 & 1.948 & 0.000 & 40.422 & 0.215 & 0.309 \\
4 & 0.188 & 49.540 & 0.364 & 0.230 & 0.176 & 0.204 & 44.931 & 0.085 & 4.283 \\
5 & 0.056 & 50.253 & 0.013 & 0.165 & 3.279 & 0.032 & 44.573 & 0.071 & 0.658 \\
6 & 0.019 & 45.536 & 0.160 & 0.014 & 0.198 & 0.523 & 50.045 & 0.182 & 3.324 \\
7 & 0.186 & 40.098 & 0.360 & 0.136 & 0.080 & 0.068 & 54.858 & 0.302 & 3.912 \\
\hline
\end{tabular}




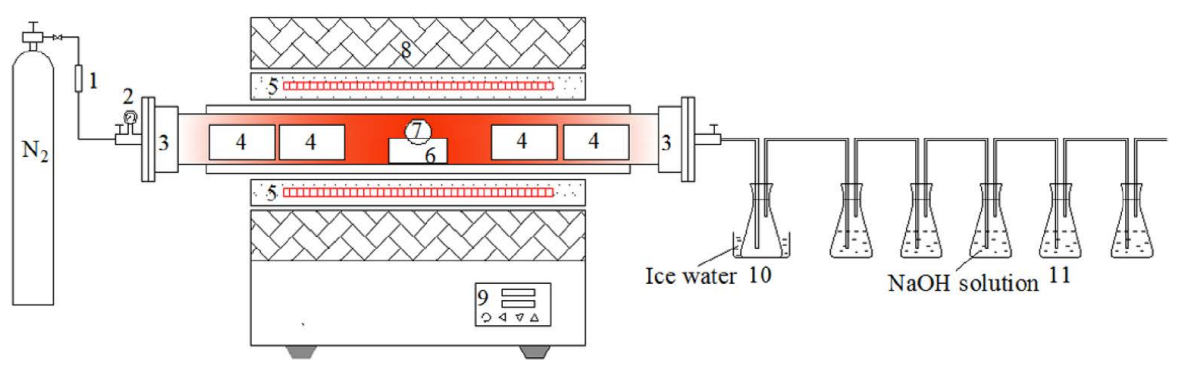

Fig. 3. Experimental apparatus. 1. Flowmeter; 2. Pressure valve; 3. Furnace cover; 4. Furnace plug; 5. Silicon carbide bar; 6. Corundum boat; 7. thermocouple; 8. Electric furnace; 9. Control cabinet; 10. Water-cooled condenser; 11. Alkali vessel. (Online version in color.)

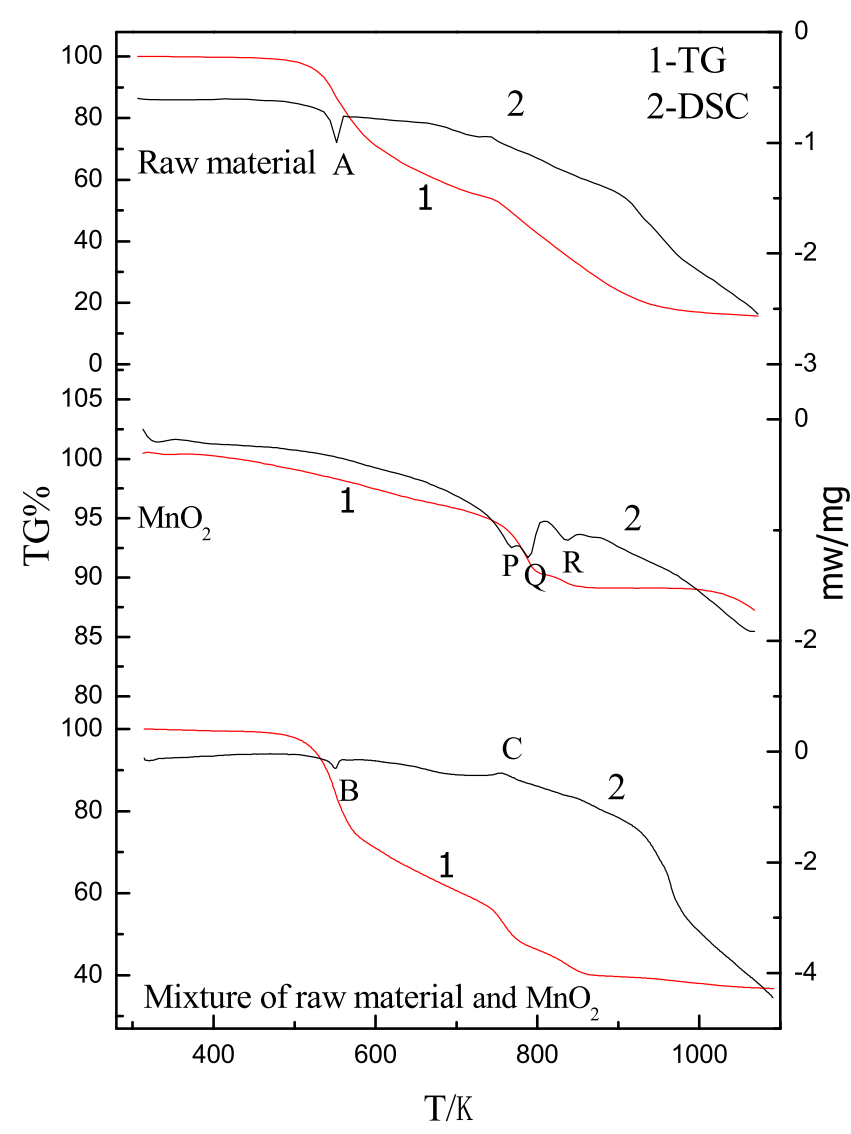

Fig. 4. TG-DSC curves for high arsenic-bearing flue dusts, $\mathrm{MnO}_{2}$, and mixture of $\mathrm{MnO}_{2}$ and high arsenic-bearing flue dusts $\left(\mathrm{MnO}_{2}\right.$ amount of $\left.15.00 \%\right)$. (Online version in color.)

scanning rate was $8^{\circ} / \mathrm{min}$ and $2 \theta$ was $10-90^{\circ}, \mathrm{D} / \max -3 \mathrm{~B}$, Rigaku Corporation of Japan). The thermodynamic data of species were given by FactSage thermochemical software. Mathematical expressions of the arsenic and antimony volatilization rates were separately defined as:

$$
\begin{aligned}
& R=\left(1-\frac{\mathrm{M}_{\mathrm{T}} \times \mathrm{W}_{0}}{\mathrm{M}_{\mathrm{C}} \times \mathrm{W}_{\mathrm{C}}}\right) \times 100 \% \\
& R^{\prime}=\left(1-\frac{\mathrm{M}_{\mathrm{T}} \times \mathrm{W}_{0}^{\prime}}{\mathrm{M}_{\mathrm{C}} \times \mathrm{W}_{C}^{\prime}}\right) \times 100 \%
\end{aligned}
$$

Where, $\mathrm{M}_{\mathrm{C}}$ stands for the mass of the high arsenic-bearing flue dust used, $\mathrm{W}_{\mathrm{C}}$ and $\mathrm{W}_{C}$ ' for the arsenic and antimony contents in the origin high arsenic-bearing flue dust, $\mathrm{M}_{\mathrm{T}}$ for total mass of the roasted residue, $\mathrm{W}_{0}$ and $\mathrm{W}_{0}$, for the arsenic and antimony contents in the roasted residue. FactSage

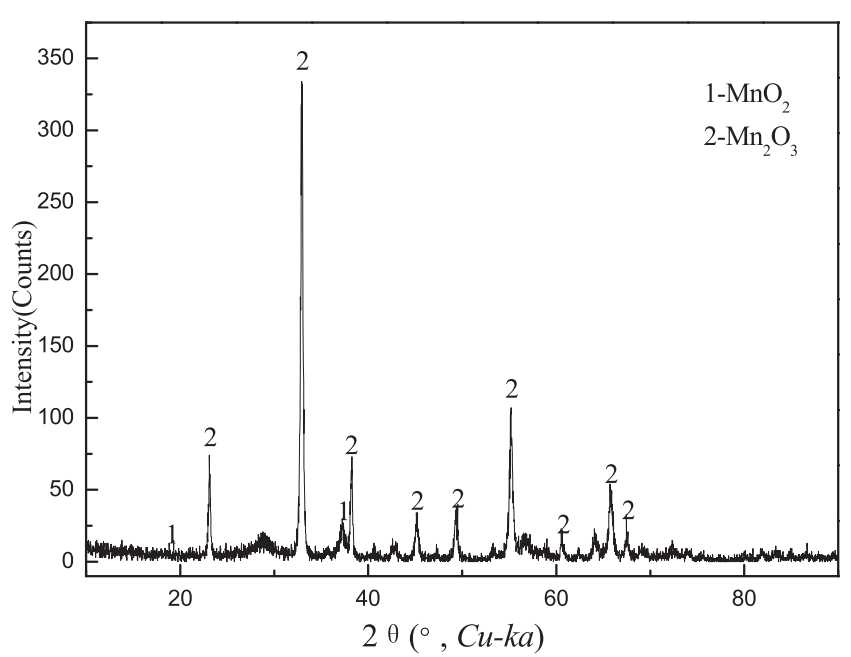

Fig. 5. XRD pattern of the roasted product of $\mathrm{MnO}_{2}$ at roasting temperature of $723 \mathrm{~K}$.

was used to calculate the mineral phase composition during roasting of mixtures of high arsenic-bearing flue dusts and $\mathrm{MnO}_{2}$, and calculation parameters were set at $1 \mathrm{~atm}$ pressure of shielding gas.

\section{Thermo-chemical Behavior of the Mixture of $\mathrm{MnO}_{2}$ and High Arsenic-bearing Flue Dusts}

Figure 4 shows TG-DSC curves of high arsenic-bearing flue dusts, $\mathrm{MnO}_{2}$, and mixture of them $\left(\mathrm{MnO}_{2}\right.$ addition amount of $15.00 \%)$ under $\mathrm{N}_{2}$ atmosphere. Two endothermic peaks at $552.0 \mathrm{~K}$ (A and B points) are detected in the DSC measurements for high arsenic-bearing flue dusts and the mixture, which are related to the melting of $\mathrm{As}_{2} \mathrm{O}_{3}$ in the raw material. At 712.2-805.7 K, two noticeable endothermic peaks ( $\mathrm{P}$ and $\mathrm{Q}$ points) are detected in the DSC measurement for $\mathrm{MnO}_{2}$, and each of them corresponds to a weight-loss stage. They are attributed to the decomposition of $\mathrm{MnO}_{2}$, generating $\mathrm{Mn}_{2} \mathrm{O}_{3}$ (Fig. 5) and $\mathrm{O}_{2}$. There is another endothermic peak ( $\mathrm{R}$ point) as a shoulder appearing near $836.6 \mathrm{~K}$, which is also related to the $\mathrm{MnO}_{2}$ decomposition. Different from that for $\mathrm{MnO}_{2}$, the DSC curve for the mixture shows an obvious exothermic peak ( $\mathrm{C}$ point) at 713.4-790.5 K. It may be related to the oxidation of high arsenic-bearing flue dusts (especially for phases of As and $\mathrm{Sb}$ ) by $\mathrm{MnO}_{2}$ or $\mathrm{O}_{2}$ generated from $\mathrm{MnO}_{2}$ decomposition. In addition, the obvious difference of decrease in weight between high arsenic-bearing flue dusts and the mixture indicates that $\mathrm{MnO}_{2}$ can oxidize the flue dust distinctly with 
temperature being higher than $713.4 \mathrm{~K}^{21)}$

\section{Results and Discussion}

\subsection{Effect of Roasting Temperature}

In order to investigate the effect of roasting temperature on the separation efficiency of arsenic and antimony, experiments were performed at $573.0-823.0 \mathrm{~K}$ while keeping other parameters constant as: roasting time $120 \mathrm{~min}, \mathrm{~N}_{2}$ flow rate $5.00 * 10^{-6} \mathrm{~m}^{3} / \mathrm{s}$, and $\mathrm{MnO}_{2}$ addition amount of $12.5 \%$.

Figure 6 shows arsenic and antimony volatilization rates both increase with roasting temperature with or without $\mathrm{MnO}_{2}$ addition. Temperature has an effect mainly on vapor pressures of volatile species shown as Fig. 7 and they increase with temperature, causing increase of volatilization rates of arsenic and antimony in Fig. 6. The $\mathrm{As}_{2} \mathrm{O}_{3}$ and $\mathrm{Sb}_{2} \mathrm{O}_{3}$ could be both oxidized to high valence oxides by $\mathrm{MnO}_{2}$ (Eqs. (3)-(4)) during the roasting process, and volatilization rates of them should be decreased with $\mathrm{MnO}_{2}$ addition from the point of view of thermodynamics. The standard Gibbs free energy changes of Eqs. (3)-(4) at different roasting temperatures are shown in Table 3. But for As, it is different seen from Fig. 6. Though the vapor pressure of $\mathrm{As}_{2} \mathrm{O}_{5}$ is low and its volatilization is hard to be carried out at the roasting temperature, evaporation of

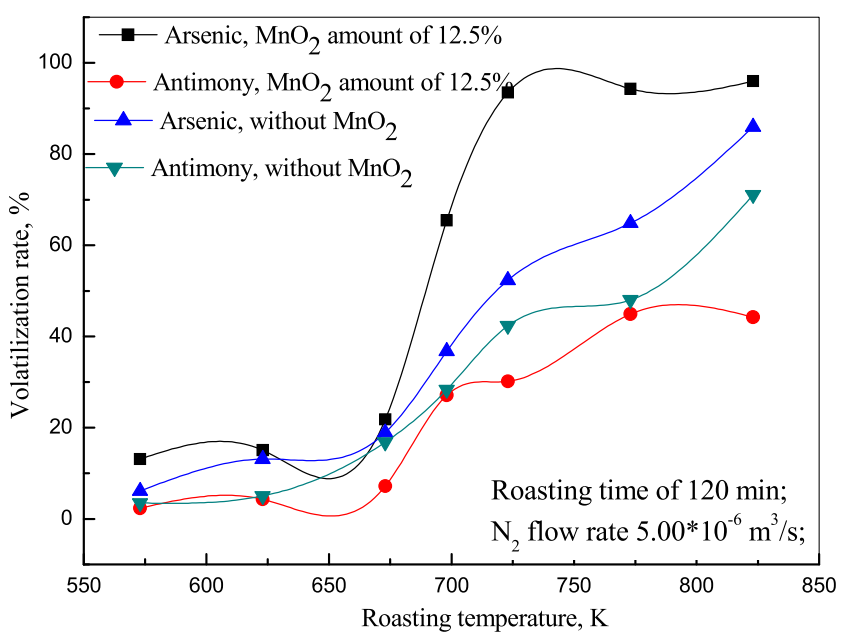

Fig. 6. Effect of roasting temperature on arsenic and antimony volatilization rates. (Online version in color.)

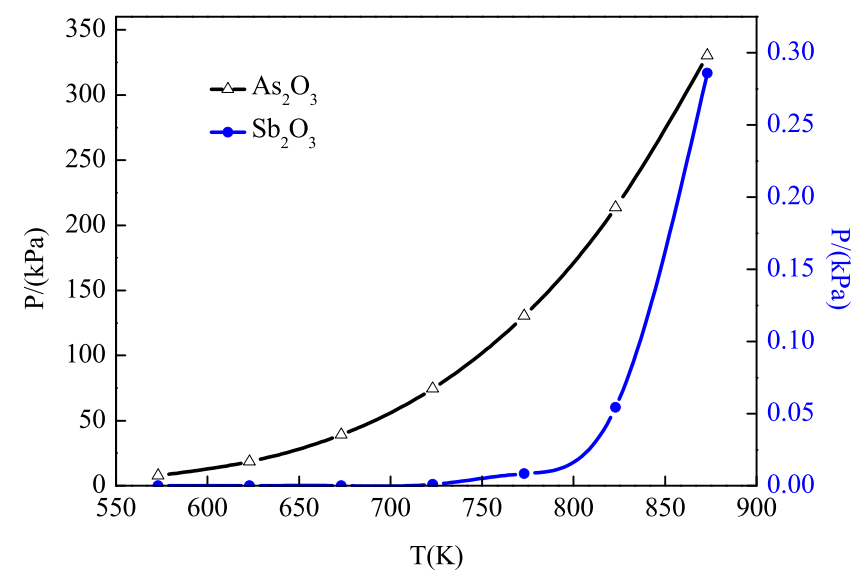

Fig. 7. Vapor pressures of $\mathrm{As}_{2} \mathrm{O}_{3}$ and $\mathrm{Sb}_{2} \mathrm{O}_{3}$ change with temperature. (Online version in color.)
$\mathrm{As}_{2} \mathrm{O}_{3}$ appears earlier than it being oxidized to $\mathrm{As}_{2} \mathrm{O}_{5}$ for its strong volatility. Meanwhile, structures of some As-Sb complicated phases (Fig. 2 and Table 2) might be destroyed after the $\mathrm{Sb}_{2} \mathrm{O}_{3}$ being oxidized to $\mathrm{Sb}_{2} \mathrm{O}_{4}$ (Fig. 8), causing this arsenic continues to volatile and the arsenic volatilization rate increases. For the purpose of increasing separation efficiency of arsenic and antimony, the roasting temperature is determined as $723.0 \mathrm{~K}$.

$$
\begin{aligned}
\mathrm{As}_{2} \mathrm{O}_{3}+3 \mathrm{MnO}_{2} & =\mathrm{Mn}_{3} \mathrm{O}_{4}+\mathrm{As}_{2} \mathrm{O}_{5} \\
2 \mathrm{Sb}_{2} \mathrm{O}_{3}+3 \mathrm{MnO}_{2} & =\mathrm{Mn}_{3} \mathrm{O}_{4}+2 \mathrm{Sb}_{2} \mathrm{O}_{4}
\end{aligned}
$$

\subsection{Effect of Amount of $\mathrm{MnO}_{2}$ Addition}

The $\mathrm{MnO}_{2}$ addition amount is one of the most important parameters in the selective oxidation process. Antimony and arsenic volatilization rates were examined by varying the $\mathrm{MnO}_{2}$ addition amount from $12.5 \%$ to $30.5 \%$.

Most arsenic evaporates during the roasting process at 723.0 K seen from Fig. 6, and the binary phase diagram of $\mathrm{MnO}_{2}-\mathrm{Sb}_{2} \mathrm{O}_{3}$ was used to calculate phase composition of the roasted product theoretically. ${ }^{22)}$ It can be seen from Fig. 9 that the phase diagram is segmented into 20 regions and the $\mathrm{MnO}_{2}$ content affects obviously on the phase composition. But for the temperature, it plays an inconspicuous effect. Specially, the " $\mathrm{Sb}_{2} \mathrm{O}_{4}(\mathrm{~s})$ " is transformed to " $\mathrm{SbO}_{2}(\mathrm{~s})$ " at about $788.0 \mathrm{~K}$, from region " 3 " to " 4 ", " 8 " to " 7 " and " 15 " to " 16 ", respectively. When the roasting temperature is 723.0 K, Fig. 9 and Table 4 show that with increasing content of $\mathrm{MnO}_{2}, \mathrm{Sb}_{2} \mathrm{O}_{3}$ is firstly oxidized to $\mathrm{Sb}_{2} \mathrm{O}_{4}$, and then to $\mathrm{Sb}_{2} \mathrm{O}_{5}$. Simultaneously, the reduction product $\mathrm{Mn}_{3} \mathrm{O}_{4}$ gradually vanishes and $\mathrm{Mn}_{2} \mathrm{O}_{3}$ is formed. The XRD patterns of roasted samples with different $\mathrm{MnO}_{2}$ addition amounts are presented in Figs. 8 and 10. They show that the main phases

Table 3. The standard Gibbs free energy changes of Eqs. (3)-(4) with temperature $(\mathrm{kJ} / \mathrm{mol})$.

\begin{tabular}{ccccccc}
\hline T/K & 573.0 & 623.0 & 673.0 & 723.0 & 773.0 & 823.0 \\
\hline Eq. (3) & -91.552 & -89.010 & -85.861 & -82.587 & -79.198 & -75.694 \\
Eq. (4) & -219.872 & -220.349 & -220.658 & -220.777 & -220.689 & -220.375
\end{tabular}

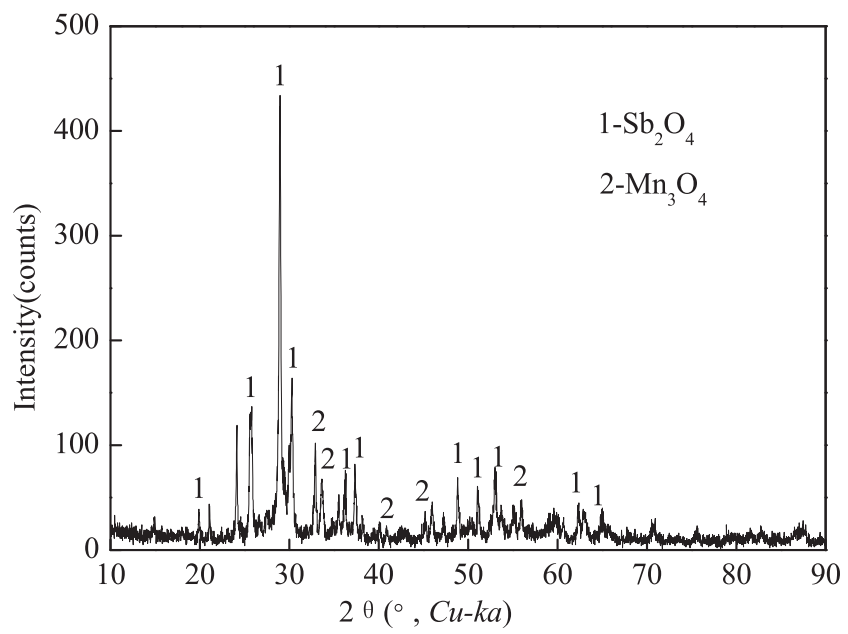

Fig. 8. XRD pattern of the roasted product at roasting temperature of $723 \mathrm{~K}$ and $\mathrm{MnO}_{2}$ amount of $12.5 \%$ 
of antimony and manganese are $\mathrm{Sb}_{2} \mathrm{O}_{4}$ and $\mathrm{Mn}_{3} \mathrm{O}_{4}$ respectively. From a comparison of mineral phases calculated by FactSage between those from XRD, it is found that $\mathrm{Sb}_{2} \mathrm{O}_{3}$ is not detected in the XRD patterns, the reason for which may be that the $\mathrm{Sb}_{2} \mathrm{O}_{3}$ has evaporated and been separated from the roasted residues. In addition, some part of $\mathrm{As}_{2} \mathrm{O}_{3}$ can be oxidized and immobilized in the form of $\mathrm{MnAsO}_{4}$ when $\mathrm{MnO}_{2}$ amount is excessive (Fig. 10), resulting in decrease of arsenic volatilization rate (Fig. 11). Figure 11 shows that the

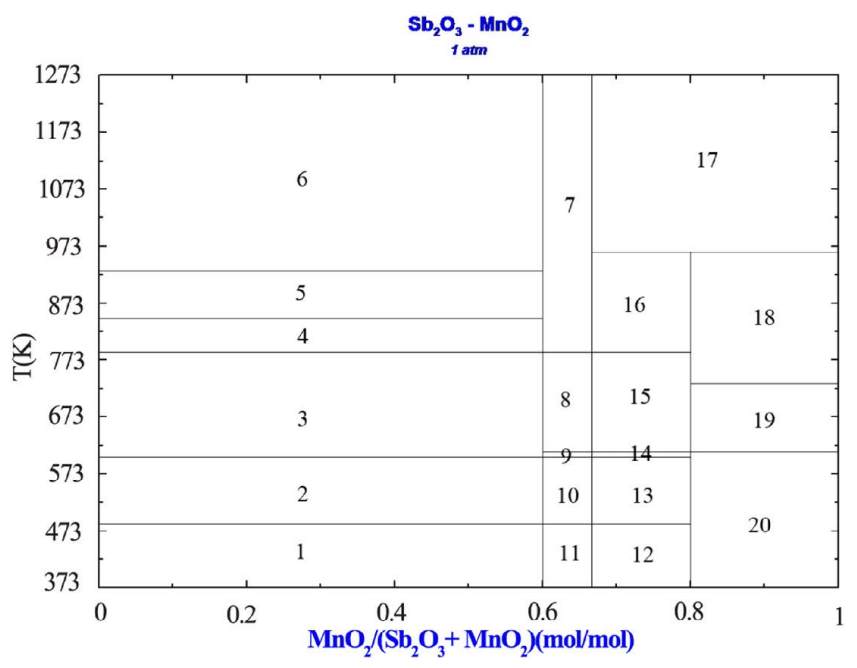

Fig. 9. Binary phase diagram of $\mathrm{MnO}_{2}-\mathrm{Sb}_{2} \mathrm{O}_{3}$. (Online version in color.)

Table 4. Phase composition in the binary phase diagram of $\mathrm{MnO}_{2}-\mathrm{Sb}_{2} \mathrm{O}_{3}$.

\begin{tabular}{|c|c|}
\hline 1. & I: $\mathrm{Sb}_{2} \mathrm{O}_{4}(\mathrm{~s})+\mathrm{Mr}$ \\
\hline $3(\mathrm{~s})$ & ${ }_{3}(\mathrm{~s})+\mathrm{Sb}_{2} \mathrm{O}_{4}(\mathrm{~s})$ \\
\hline$(\mathrm{s})+\mathrm{Sb}_{2} \mathrm{O}_{3}(\mathrm{~s})$ & 3: $\mathrm{SbO}_{2}(\mathrm{~s})+\mathrm{Mn}_{2} \mathrm{O}_{3}(\mathrm{~s})+\mathrm{Sb}_{2} \mathrm{O}_{5}(\mathrm{~s})$ \\
\hline-5 & 1: $\mathrm{Sb}_{2} \mathrm{O}_{4}(\mathrm{~s})+\mathrm{Mn}_{2} \mathrm{O}_{3}(\mathrm{~s})+$ \\
\hline $\mathrm{O}_{3}(\mathrm{~s} 2)$ & 15: $\mathrm{Sb}_{2} \mathrm{O}_{4}$ \\
\hline $\mathrm{ln}_{3} \mathrm{O}_{4}(\mathrm{~s})$ & 16: $\mathrm{SbO}_{2}(\mathrm{~s})+\mathrm{Mn}_{2} \mathrm{O}_{3}(\mathrm{~s} 2)+\mathrm{Sb}_{2} \mathrm{O}_{5}(\mathrm{~s})$ \\
\hline $\mathrm{O}_{4}(\mathrm{~s})$ & $\mathrm{O}_{2}(\mathrm{~g})+\mathrm{SbO}_{2}(\mathrm{~s})$ \\
\hline 8: $\mathrm{S}$ & 18: \\
\hline $\mathrm{n}_{2} \mathrm{O}_{3}(\mathrm{~s})+\mathrm{Mn}_{3} \mathrm{O}_{4}(\mathrm{~s})$ & 19: $\mathrm{Mn}_{2} \mathrm{O}_{3}(\mathrm{~s} 2)+\mathrm{MnC}$ \\
\hline 10: $\mathrm{SbO}_{2}(\mathrm{~s})+\mathrm{Mn}_{2} \mathrm{O}_{3}(\mathrm{~s})+\mathrm{Mn}_{3} \mathrm{O}_{4}(\mathrm{~s})$ & 20: $\mathrm{MnO}_{2}(\mathrm{~s})+\mathrm{Mn}_{2} \mathrm{O}_{3}(\mathrm{~s})+\mathrm{Sb}_{2} \mathrm{O}_{5}(\mathrm{~s})$ \\
\hline
\end{tabular}

arsenic volatilization rate decreases from $93.48 \%$ to $85.58 \%$ and that for antimony decreases from $30.18 \%$ to $11.11 \%$ with increasing $\mathrm{MnO}_{2}$ amount from $12.5 \%$ to $30.5 \%$. Giving consideration on increasing separation efficiency of arsenic and antimony, the $\mathrm{MnO}_{2}$ addition amount of $20.5 \%$ is determined as the optimal condition.

\section{3. $\quad$ Effect of Roasting Time}

Volatilization rates of arsenic and antimony phases were distinguished due to the vapor pressure difference between them. Figure 12 shows variations of arsenic and antimony volatilization rates as a function of roasting time. The arsenic volatilization rate increases gradually in the primary 90 min, from $25.62 \%$ to $90.06 \%$, and then remains nearly constant. Comparatively, that for antimony always increases, from $3.18 \%$ to $20.33 \%$ with the roasting time from $30 \mathrm{~min}$ to $150 \mathrm{~min}$. To decrease the antimony loss and improve arsenic removal rate, the roasting time is fixed at $90 \mathrm{~min}$.

For the purpose of increasing separation and recovery rates of antimony, the above results suggest that the selective oxidation roasting of high arsenic-bearing flue dusts using $\mathrm{MnO}_{2}$ should be carried out at roasting temperature of $723.0 \mathrm{~K}, \mathrm{MnO}_{2}$ amount of $20.5 \%$, and roasting time of $90 \mathrm{~min}$. Under the optimal conditions, the volatilization rate of arsenic is about $90.06 \%$ and for antimony is only about $6.89 \%$, indicating that arsenic can be separated effectively

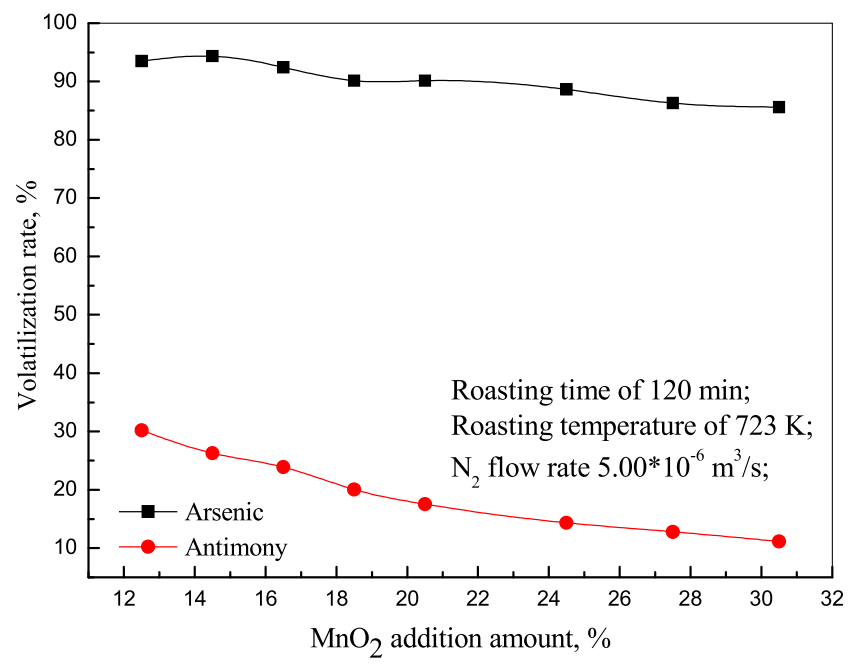

Fig. 11. Effect of $\mathrm{MnO}_{2}$ addition amount on arsenic and antimony volatilization rates. (Online version in color.)

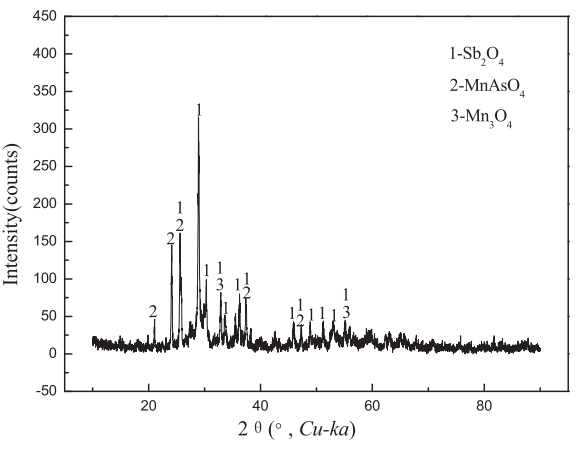

$\mathrm{MnO}_{2}$ amount of $24.5 \%$

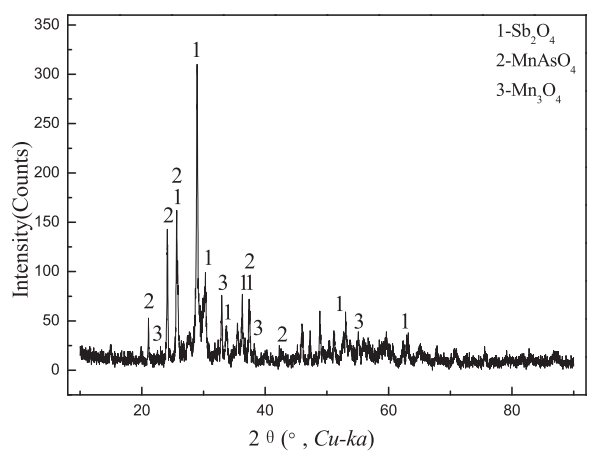

$\mathrm{MnO}_{2}$ amount of $27.5 \%$

Fig. 10. XRD patterns of the roasted products at roasting temperature of $723 \mathrm{~K}$ with $\mathrm{MnO}_{2}$ amount of $24.5 \%$ and $27.5 \%$. 


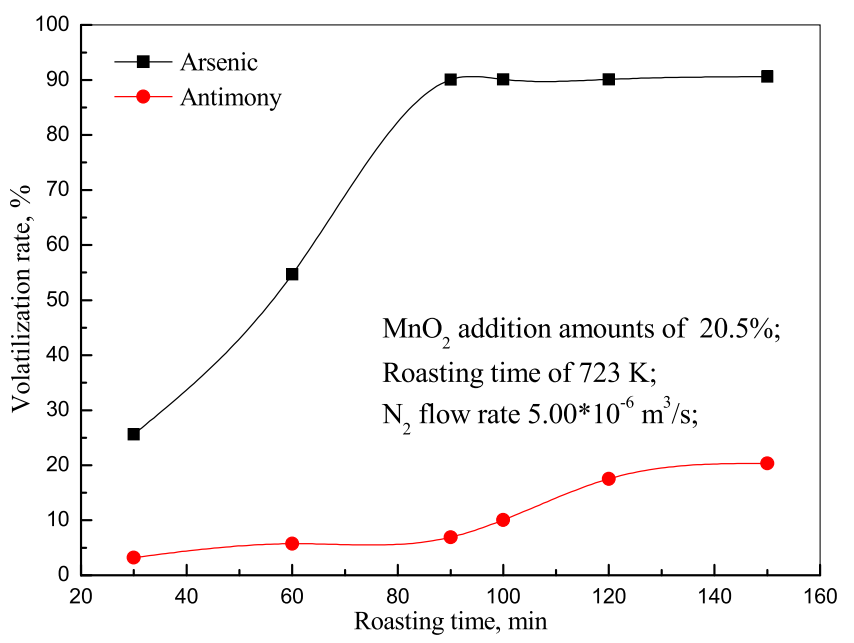

Fig. 12. Effect of roasting time on arsenic and antimony volatilization rates. (Online version in color.)

from high arsenic-bearing flue dusts through a low temperature roasting using $\mathrm{MnO}_{2}$ as an additive. Then the antimony in the roasted products can be reclaimed through a reduction roasting and dust collection process. ${ }^{23)}$

\section{Conclusions}

A selective oxidation roasting process was developed for the separation and recovery of antimony from high arsenicbearing flue dusts. Though $\mathrm{As}_{2} \mathrm{O}_{3}$ could be oxidized to $\mathrm{As}_{2} \mathrm{O}_{5}$ by $\mathrm{MnO}_{2}$ from the point of view of thermodynamics during the roasting process, the evaporation for $\mathrm{As}_{2} \mathrm{O}_{3}$ appeared earlier than it being oxidized attributed to strong volatility of it and most arsenic volatized. Meanwhile, the $\mathrm{MnO}_{2}$ has a positive effect with it amount in a certain range for the arsenic volatilization, for the reason that structures of some As-Sb complicated phases were destroyed after the $\mathrm{Sb}_{2} \mathrm{O}_{3}$ being oxidized to $\mathrm{Sb}_{2} \mathrm{O}_{4}$ by $\mathrm{MnO}_{2}$ and this arsenic continued to volatile. The $\mathrm{MnO}_{2}$ selective oxidation provided a good separation of arsenic and antimony under the conditions of roasting temperature of $723.0 \mathrm{~K}, \mathrm{MnO}_{2}$ amount of $20.5 \%$, and roasting time of $90 \mathrm{~min}$, with which about $90.06 \%$ arsenic and only about $6.89 \%$ went into the smoke. The residual antimony existing in the roasted products, mainly in the form of $\mathrm{Sb}_{2} \mathrm{O}_{4}$, could be reclaimed through a process of reduction roasting and dust collection.

\section{Acknowledgments}

The authors wish to express thanks to National Science Fund for Distinguished Regional Scholars (51564034) and Scientific and Technological Leading Talent Projects in Yunnan Province (No. 2015HA019) for financial support of this research.

\section{REFERENCES}

1) M. Lundgren, U. Leimalm, G. Hyllander, L. S. Okvist and B. Bjorkman: ISIJ Int., 50 (2010), No. 11, 1570.

2) M. P. Taylor, D. Camenzuli, L. J. Kristensen, M. Forbes and S. Zahran: Environ. Pollut., 178C (2013), 447.

3) Y. L. Zhang and E. Kasai: ISIJ Int., 44 (2004), No. 9, 1457.

4) Z. F Xu, Q. Li and H. P. Nie: Trans. Nonferr. Met. Soc. China, 20 (2010), z1, s176

5) V. Montenegro, H. Sano and T. Fujisawa: Miner. Eng., 49 (2013), No. 8, 184.

6) Y. Chen, T. Liao, G. B. Li, B. Z. Chen and X. C. Shi: Miner. Eng., 39 (2012), No. 12, 23.

7) C. S. Chen, Y. J. Shih and Y. H. Huang: Waste Manag., 52 (2016), 212.

8) M. Vitkova, V. Ettler, J. Hyks, T. Astrup and B. Kribek: Appl. Geochem., 26 (2011), No. 3, S263.

9) F. Bakhtiari, H. Atash, M. Zivdar, S. Seyedbagheri and M. S. Fazaelipoor: J. Ind. Eng. Chem., 17 (2011), No. 1, 29.

10) R. A. Shawabkeh: Hydrometallurgy, 104 (2010), No. 1, 61.

11) A. Morales, M. Cruells, A. Roca and R. Bergo: Hydrometallurgy, 105 (2010), No. 1, 148

12) X. Y. Guo, J. Shi, Y. Yia, Q. H. Tian and D. Li: J. Environ. Chem. Eng., 3 (2015), No. 1, 2236.

13) Y. H. Li, Z. H. Liu, Q. H. Li, Z. W. Zhao, Z. Y. Liu and L. Zeng: Hydrometallurgy, 108 (2011), No. 3-4, 165.

14) I. Mihajlovic, N. Strbac, Z. Zivkovic, R. Kovacevic and M. Stehernik: Miner. Eng., 20 (2007), No. 1, 26.

15) J. S. Wang: Copp. Ind. Eng., 1 (2005), 27 (in Chinese).

16) V. Montenegro, H. Sano and T. Fujisawa: Miner. Eng., 49 (2010), No. 8, 184.

17) S. Kashiwakura, H. Ohno, K. Matsubae-Yokoyama, Y. Kumagai, H. Kubo and T. Nagasaka: J. Hazard. Mater., 181 (2010), No. 1-3, 419.

18) W. Tongamp, Y. Takasaki and A. Shibayama: Hydrometallurgy, 101 (2010), No. 1, 64.

19) X. Y. Guo, Y. Yi, J. Shi and Q. H. Tian: Trans. Nonferr Met. Soc. China, 26 (2016), No. 2, 575.

20) E. Vircikova and M. Havlik: JOM, 51 (1999), No. 9, 20.

21) B. Boyanov, A. Peltekov and V. Petkova: Thermochim. Acta, 586 (2014), No. 8, 9.

22) Y. L. Zhao, Y. M. Zhang, S. X. Bao, T. J. Chen and J. Han: Int. J. Miner. Process., 124 (2013), No. 6, 150.

23) A. Aracena, O. Jerez and C. Antonucci: Trans. Nonferr. Met. Soc. China, 26 (2016), No. 1, 294. 